\title{
Correction to: Skills and key education needed for clinical librarians: an exploratory study from the librarians' perspectives
}

Maryam Zarghani', Leila Nemati-Anaraki², Zahra Dinpajoo ${ }^{1}$, Arezoo Ghamgosar ${ }^{1}$, Sedegheh Khani ${ }^{1}$ and Maryam Khazaee-Pool ${ }^{3,4^{*}}$ (D)

\section{Correction to: BMC Med Inform Decis Mak (2021) 21:40} https://doi.org/10.1186/s12911-021-01601-y

Following publication of the original article [1], it was reported that Arezoo Ghamgosar's name was erroneously published as 'Arezo Ghamgosar'.

The original article has been corrected.

\section{Publisher's Note}

Springer Nature remains neutral with regard to jurisdictional claims in published maps and institutional affiliations.

\begin{abstract}
Author details
${ }^{1}$ School of Health Management and Medical Information Science, Iran University of Medical Sciences, Tehran, Iran. ${ }^{2}$ Department of Medical Library and Information Sciences, School of Health Management and Medical Information Science, Iran University of Medical Sciences, Tehran, Iran. ${ }^{3}$ Department of Public Health, School of Health, Mazandaran University of Medical Sciences, Sari, Iran. ${ }^{4}$ Health Sciences Research Center, Addiction Research Institutes, Mazandaran University of Medical Sciences, Sari, Iran.
\end{abstract}

Published online: 04 October 2021

\section{Reference}

1. Zarghani M, Nemati-Anaraki L, Dinpajoo Z, et al. Skills and key education needed for clinical librarians: an exploratory study from the librarians' perspectives. BMC Med Inform Decis Mak. 2021;21:240. https://doi.org/ 10.1186/s12911-021-01601-y. 